\title{
DEVELOPMENT OF TABLETS CONTAINING SOLID DISPERSION OF IBUPROFEN MANUFACTURED BY HOT MELT IMPREGNATION PROCESS
}

\author{
KAMIL GARBERA ${ }^{1}$, KATARZYNA WOŚ-LATOSI ${ }^{2}$ and WIESŁAW SAWICKI ${ }^{3 *}$
}

${ }^{1}$ Adamed Pharma S.A., Formulation and Technology Department R\&D, Pieńków 149, 05-152 Czosnów, Poland

${ }^{2}$ Adamed Pharma S.A., Preformulation Department R\&D, Pieńków 149, 05-152 Czosnów, Poland

${ }^{3}$ Medical University of Gdansk, Department of Physical Chemistry, Hallera 107, 80-416 Gdańsk, Poland

\begin{abstract}
The main assumption of the given study was to develop tablets containing amorphous ibuprofen by hot melt extrusion process. However, the proposed manufacturing procedure demonstrates quite a few differences in comparison to the conventional hot melt extrusion. Accurately the given manufacturing procedure has been called a hot melt impregnation due to the process characteristics. As a product of the described process, a fine free-flowing extrudate is obtained. Four different compositions have been proposed. Materials prepared by hot melt impregnation technique have been extensively examined in terms of physicochemical properties and then were subjected to tablet compression process. Obtained tablets were examined in terms of thermodynamic stability and compared to a marketed product containing ibuprofen. The result has shown much higher dissolution for prepared formulations, higher of $50 \%$ at $30 \mathrm{~min}$ time point during the dissolution test in $0.1 \mathrm{M} \mathrm{HCL}$ medium.
\end{abstract}

Keywords: hot melt extrusion, hot melt impregnation, solid dispersion, amorphization, ibuprofen, solubility enhancement

Due to patient comfort and compliance oral delivery is the preferred route of administration. To obtain a therapeutic effect of a drug in the system, the drug needs to be available at the target site in the therapeutic range (1). For oral administration, this is achieved when a sufficiently high amount of drug is dissolved in the gastrointestinal tract, absorbed, and distributed via the bloodstream to reach the target.

One of the major challenges in pharmaceutical development is still growing number of poorly water- soluble new compounds. Poor water solubility is often a factor limiting bioavailability (2). These compounds constitute more than $70 \%$ of all drugs available on the market today (3). Accordingly, while being highly potent in vitro, these drugs lack therapeutic efficacy in vivo, mainly because of not reaching a high enough concentration in the site of absorption, i.e., GI lumen. Enhancing the dissolution of the drug in the GI is, therefore, a challenge in drug discovery (4). Therefore poorly water-soluble

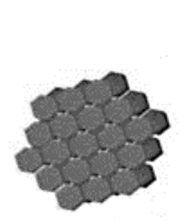

Crystalline API

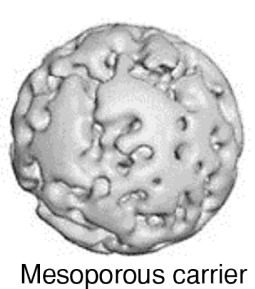

Figure 1. Schematic diagram of carrier impregnation by a melted drug in an HME process

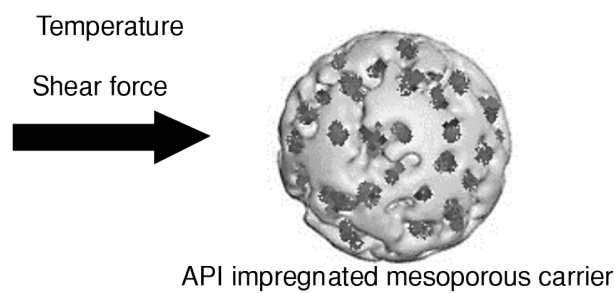

API impregnated mesoporous carrier

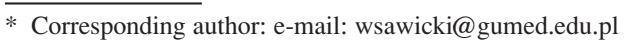


drugs are in the great interest of formulation scientists around the world. Conducted research is focused on ways to improve aqueous solubility and thus potentially bioavailability of poorly water-soluble compounds (5).

Solubility or dissolution rate can be improved by different types of drug molecule modifications. In general, three different approaches can be distinguished from a wide variety of possibilities for solubility enhancement. These approaches can be grouped into solubility improvement on the molecular, colloidal or particular level (6). Chemical modifications include a variation of the $\mathrm{pH}$ of the final drug formulation (7), derivatization, salt formations (8), prodrugs (9) or cocrystals creations (10). On the colloidal level, the solubility is increased by emulsions, microemulsions (11), or lipid-based waterfree formulations (12) or using cyclodextrins (13). The solubility enhancement on the particulate level includes nanosizing, creation of metastable polymorphs or drug amorphization $(14,15)$.

Recent attempts to resolve drug solubility issues include techniques such as particle size reduction (16), spray drying $(17,18)$, co-evaporation or co-precipitation (19), freeze-drying (20), supercritical fluid processing (SFP) (21), cryogrinding (22, $23)$ and also hot-melt extrusion (HME) $(24,25)$.

Hot melt extrusion is a continuous process originating from plastic and food industries. At the end of the last century, HME has been successfully implemented in pharmaceutical technology. Since then HME is a growing technology of numerous application possibilities (26). The main idea of HME is to disperse or dissolve API within polymeric matrix to form a solid dispersion in either crystalline or amorphous form, or ideally to create a one phase solid solution system (27).

Use of an amorphous form of the active substance is a well-known solution to improve the oral bioavailability of poorly soluble drugs. The amorphous systems can be characterized as the ones possessing the highest possible energy levels within the solid state forms. This property can offer higher sol- ubility, faster dissolution rate and thereby the potential bioavailability improvement. As the main disadvantage of amorphous state exploitation, one has to mention that thermodynamic stability is always a challenge for amorphous substance. Physical instability leads to a conversion into a crystalline state (28).

Besides standard polymeric approach, there are reported applications with use of inorganic excipients as drug carries for increase dissolution rates of poorly water-soluble drugs (29). One of the interesting material which can be used as a drug carrier in the hot melt extrusion process is a fine, ultra-light granulate of magnesium aluminometasilicate (Neusilin ${ }^{\circledR}$ US2). Due to its large surface area (> $300 \mathrm{~m} / \mathrm{g}$ ), porous nature, high mechanical and thermal stability Neusilin US2 is a great candidate for API carrier (30). Additionally, polyvinyl alcohol (PVA) was chosen as a solubility enhancer of ibuprofen (31). Selected grade of Parteck MXP was specially designed and characterized for HME applications (glass transition temperature $\left(\mathrm{T}_{\mathrm{o}}\right) 40-45^{\circ} \mathrm{C}$, melting point $\left(\mathrm{T}_{\mathrm{o}}\right) 170^{\circ} \mathrm{C}$, thermal degradation above $\left.250^{\circ} \mathrm{C}\right)(32)$.

The main assumption of the given study was to develop tablets containing amorphous ibuprofen by utilizing inorganic excipient as a drug carrier in a hot melt extrusion process. However, the proposed manufacturing procedure demonstrates quite a few differences in comparison to a conventional hot melt extrusion process. Accurately the presenting manufacturing procedure has been called a hot melt impregnation due to the process characteristics and the nature of obtained material. Such an approach can provide new and interesting insight into pharmaceutical research and product development.

\section{MATERIALS AND METHODS}

\section{Materials}

Ibuprofen ( $\geq 98 \%$ ) was purchased from Strides Shasun Ltd, Magnesium aluminometasilicate (Neusilin ${ }^{\circledR}$ US2) was kindly donated by Fuji

Table 1. Detailed composition of proposed formulations.

\begin{tabular}{|c|c|c|c|c|}
\hline & IBU01E & IBU02E & IBU03E & IBU04E \\
\cline { 2 - 5 } & \multicolumn{3}{|c|}{$\% \mathrm{w} / \mathrm{w}$} & 50 \\
\hline Ibuprofen & 33.3 & 45 & 40 & 0 \\
\hline Polyvinyl alcohol (Parteck MXP) & 33.3 & 20 & 20 & 50 \\
\hline $\begin{array}{c}\text { Magnesium aluminometasilicate } \\
\text { (Neusilin US2) }\end{array}$ & 33.3 & 35 & 40 & 5 \\
\hline
\end{tabular}




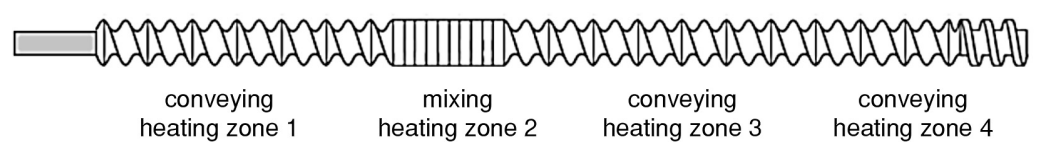

Figure 2. Screws configuration used in the hot melt impregnation process

Chemical Industries Co., Ltd. (Japan). Polyvinyl alcohol PVA (Parteck MXP) was kindly donated by Merck KGaA.

\section{Methods \\ Preparation of samples \\ Hot plate melting}

Hot plate melting was used to simulate the physical behavior of ibuprofen during the hot melt extrusion process. Pure ibuprofen was placed into a Petri dish and put on a hot plate. The temperature was set at $85^{\circ} \mathrm{C}$ and heating was kept until all load of active substance melted down. Melted material then was kept at room temperature to solidify for 2 hours.

\section{Preparation of ibuprofen physical mixtures}

Raw materials were weighed and sieved through $1.0 \mathrm{~mm}$ sieve. Each composition was blended in a $2 \mathrm{~L}$ stainless steel bin container rotated at 12 rotates per minute (RPM) for $10 \mathrm{~min}$. Four different compositions have been proposed and shown in Table 1.

\section{Hot melt extrusion/impregnation process}

HME is a process of applying heat and mechanically created pressure, to a mixture of processed raw materials and forcing it through a die in a melted state to shape a long elastic strand. Proposed process application is distinguished by the form of the product. In given application blended raw material (mixture of ibuprofen, Neusilin and PVA) is transported through the extruder's barrel by co-rotating twin screws. Temperature applied to the barrel heats raw material causing melting of the low-melting point substances, excluding inorganic carrier (Neusilin). Melted substances start to penetrate into the volume of open Neusilin pores. Capillary effect is considered as a driving force of this phenomenon. As a product of the described process, a fine freeflowing extrudate is obtained and the extruder does not need a die at the end of the barrel. The extrudate literally flows out of the barrel and the die could cause a blockage. Due to the different physical form of the extrudate, a name of hot melt impregnation process was proposed for this application.
The process was conducted in a twin screw (co-rotating) extruder ThreeTec ZE 18 with a length to screw diameter ratio (L/D) $20: 1$, screw diameter $18 \mathrm{~mm}$, possessing 4 heating zones. To choose optimal process temperature, feeding rate and screw speed have been set constant at $120 \mathrm{~g} / \mathrm{h}$ and $25 \mathrm{RPM}$ respectively, retention time at the given setup was roughly $1.5 \mathrm{~min}$. Screw configuration was also constant and has been proposed as it is shown in Figure 2. Only a short mixing section has been applied to the conveying elements. Mixing elements tasks were to evenly distribute melted ibuprofen within the rest of the material, maximizing the contact area and intensifying the absorptive effect. To optimize temperature profile ternary mixture IBU01 has been processed at temperatures varying from $110^{\circ}$ to $170^{\circ} \mathrm{C}$ in the third heating zone, the rest heating zones were kept at constant temperatures. The final temperature profile was set as $70 / 110 / 170 / 130^{\circ} \mathrm{C}$ and was applied for all prepared compositions.

\section{Preparation of tableting blends}

Each extrudate batch was blended with $3 \%$ w/w croscarmellose sodium and $1 \%$, w/w magnesium stearate in a $2 \mathrm{~L}$ volume stainless steel bin container rotated at $12 \mathrm{rpm}$ for $10 \mathrm{~min}$ and $3 \mathrm{~min}$ respectively for croscarmellose sodium and magnesium stearate.

\section{Preparation of tablets containing solid dispersion of ibuprofen}

Tablet compression has been conducted on laboratory rotary tablet press KORSCH XL100. All prepared formulations were compressed into $\varnothing 12$ $\mathrm{mm}$ biconvex round tablets, each tablet contained $200 \mathrm{mg}$ of ibuprofen in an inorganic carrier. Tablet weight varied for each formulation due to different ibuprofen content in impregnated material. Tableting blends were fed through the feeder without paddles. Rotation speed of the turret was set at 25 RPM. Pre-compression force equaled $0.5 \mathrm{kN}$, main compression force varied from $5.0 \mathrm{kN}$ to 8.0 $\mathrm{kN}$ depending on the batch. Parameters were chosen individually for each formulation to prepare similar tablets in a matter of mechanical properties (hard- 
ness $100-130 \mathrm{~N}$, disintegration time $<5.0 \mathrm{~min}$ ). Each tablets batch consisted of $96 \%$ of extrudate, $3 \%$ of croscarmellose sodium and $1 \%$ of magnesium stearate.

\section{Physicochemical analysis \\ Particle size analysis}

Particle measurement of all extruded materials was measured by dry sieving. The method involved placing the sieves on the top of each other loading a $50 \mathrm{~g}$ sample and shaking it all together for $10 \mathrm{~min}$ with a $1.5 \mathrm{~mm}$ amplitude. Retained material on each sieve has been accurately weighed.

\section{Bulk density, tapped density and flow ability}

The investigations were done according to the procedures described in Ph. Eur. Bulk and tapped density tests were performed employing an SVM tapped density tester (type svm 22, Erweka, Offenbach, Germany).

\section{Angle of repose}

The angle of repose was determined using a GTB flow ability tester with dynamic balance (Erweka, Offenbach, Germany) was used to measure flowability. A method was to determine a time flow of a preset material from a metal outlet nozzle with $15 \mathrm{~mm}$ diameter, without a stirrer. The angle between the surface of the cone formed by the tablet mass and the horizontal surface was measured using a laser beam. The test was repeated three times, and the mean value was used.

\section{Friability and tablet disintegration time tests of the tablets}

Measurements of friability and tablet disintegration time were performed following the methods described in European Pharmacopeia (Ph. Eur.) The disintegration test was performed in six replicates in distilled water at $37^{\circ} \mathrm{C}$ employing a Pharmatron DisiTest 50 (Sotax AG - Thun, Switzerland) at 30 strokes/min. Friability was performed employing the friability/abrasion tester type Pharmatron FT2 (Sotax AG - Thun, Switzerland).

\section{Hardness, weight and thickness uniformity of the tablets}

The uniformity of tablet weights, hardness, diameter, and thickness were measured according to methods described in $\mathrm{Ph}$. Eur. The thickness and diameter were measured to the nearest $0.1 \mathrm{~mm}$ on 20 randomly selected tablets using a digital pair of calipers, and the mean value was calculated. The tablet tester type Pharmatron SmartTest 50 (Sotax AG - Thun, Switzerland) was used.

\section{Scanning electron microscopy (SEM)}

Carl Zeiss EVO/LS25 SEM with a backscattered electron (BSE) detector was used to study the surface morphology of the pure active substances, excipients, physical mixtures, and extruded materials. The samples $(n=1)$ were mounted on an aluminum stage using adhesive carbon tape and placed in the microscope chamber. SEM was operating in a variable pressure mode at the nitrogen gas pressure in the chamber ranging from 60 to $100 \mathrm{~Pa}$ and at accelerating voltage of $20 \mathrm{kV}$.

\section{Differential scanning calorimetry (DSC)}

A Mettler-Toledo Star 1 (Greifensee, Switzerland) DSC was used to carry out DSC runs of the pure active substance, excipients, physical mixtures, and extrudates. About 2-5 mg of sample was placed in a sealed aluminum pan with a pierced lid. All of the examined samples were heated at $10^{\circ} \mathrm{C} / \mathrm{min}$ from $30^{\circ} \mathrm{C}$ to $200^{\circ} \mathrm{C}$ under a dry nitrogen atmosphere (nitrogen flow $30 \mathrm{~mL} / \mathrm{min}$ ).

\section{$X$-ray powder diffraction (XRPD)}

XRPD was used to determine the solid state of a pure active substance, excipients, physical mixtures and extruded materials using a Rigaku Miniflex (Tokyo, Japan) in $2 \theta / \theta$ mode. For the study purposes a $\mathrm{Cu}$ anode at $30 \mathrm{kV}$ and $15 \mathrm{~mA}$ with $\mathrm{K} \beta$ a)

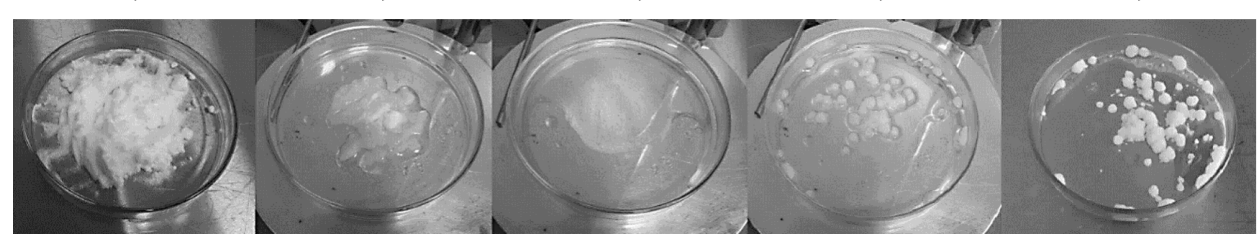

Figure 3. Melting - solidifying cycle of pure ibuprofen a) crystalline, b) partially melted, c) fully melted, d) partially solidified, e) fully solidified 


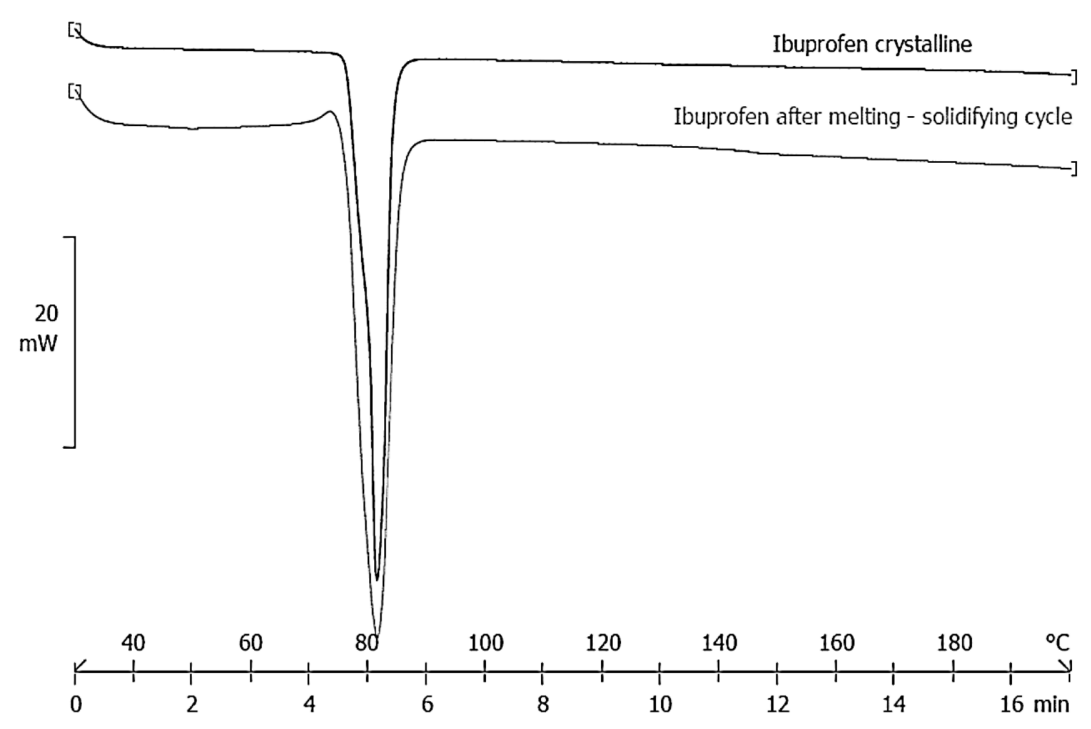

Figure 4. DSC thermograms of crystalline ibuprofen before and after melting - solidifying cycle

foil filter, variable divergence slit, fixed scattering slit at $4.2 \mathrm{~mm}$, fixed receiving slit at $0.3 \mathrm{~mm}$, Soller slit at $2.5^{\circ}$ and $\mathrm{NaI}$ scintillator as a detector was used. Each sample was scanned from 2 to $38^{\circ} 2 \theta$ with a sampling width $0.02^{\circ}$ and scanning speed $1.00 \% \mathrm{~min}$.

\section{Fourier transformation infrared spectroscopy (FTIR)}

FTIR analysis was performed on the pure active substances, excipients, physical mixtures and extruded materials using PerkinElmer Spectrum 100 (Massachusetts, USA) equipped with a PIKE Technologies MIRacle attenuated total reflectance (ATR) ZnSe single reflection plate sampling accessory (Wisconsin, USA). ATR FTIR spectra were acquired in a range from 600 to 4000 wavelength $/ \mathrm{cm}^{\circ}$.

\section{Specific surface area measurement (SSA)}

Nitrogen vapor adsorption isotherms were measured at a liquid nitrogen temperature with the Gemini VII 2390p BET SSA analyzer. Prior to the adsorption experiments, samples were outgassed under a nitrogen stream during a length of time ranging from 2 to $21 \mathrm{~h}$ at $30^{\circ} \mathrm{C}$ and for pure Neusiline US2 sample at $200^{\circ} \mathrm{C}$. The associated weight loss resulting from water/other impurities desorption was measured in each case. All SSA results obtained for the active substance, excipients physical mixtures and extruded materials were expressed as a mean value of $n=3$ measurements.

\section{Dynamic vapor sorption (DVS)}

The water sorption-desorption isotherms were obtained using a DVS Advantage 1 (Surface
Measurement Systems Ltd., London, UK) at a temperature of $25^{\circ} \mathrm{C}$. Before the start of each sorptiondesorption cycle, the sample was kept in $0 \%$ RH until constant mass was equilibrated. In each cycle, RH was raised in steps from 0 to $90 \%$ and then decreased back to $0 \%$. The rate of change in mass per time unit $(\mathrm{dm} / \mathrm{dt})=0.02 \% / \mathrm{min}$ was set as the equilibration parameter. RH change step was established at $10 \%$.

\section{In vitro dissolution tests}

In vitro dissolution study was conducted on ibuprofen tablets $200 \mathrm{mg}$ strength. Drug release was carried out in a paddle apparatus vessels field with $900 \mathrm{~mL}$ of $0.1 \mathrm{M} \mathrm{HCl}$ (paddle speed $50 \mathrm{RPM}$ ). Dissolution bath and vessels were equilibrated to 37 $\pm 0.5^{\circ} \mathrm{C}$. At predetermined time points, samples were collected $(5,10,15,20,30,45$ and $60 \mathrm{~min})$. The test was performed on DISTEK Evolution 6100. During the test, no sink conditions were fulfilled.

\section{UV-Vis spectrophotometry}

Spectrophotometric analysis was performed in real time, samples were collected automatically from dissolution vessels by peristaltic pump Agilent $8 \mathrm{VS}$ and transported directly to Agilent 8453 spectrophotometer. Samples were analyzed at $221 \mathrm{~nm}$ wavelength and compared to the standard solution.

\section{Stability studies}

Stability studies have been conducted for blistered tablets of ibuprofen manufactured in $\mathrm{HME}$ process. The product was stored at $40^{\circ} \mathrm{C}$ and $75 \%$ relative humidity in PVC blisters. The study was carried out for a period of 2 months. 


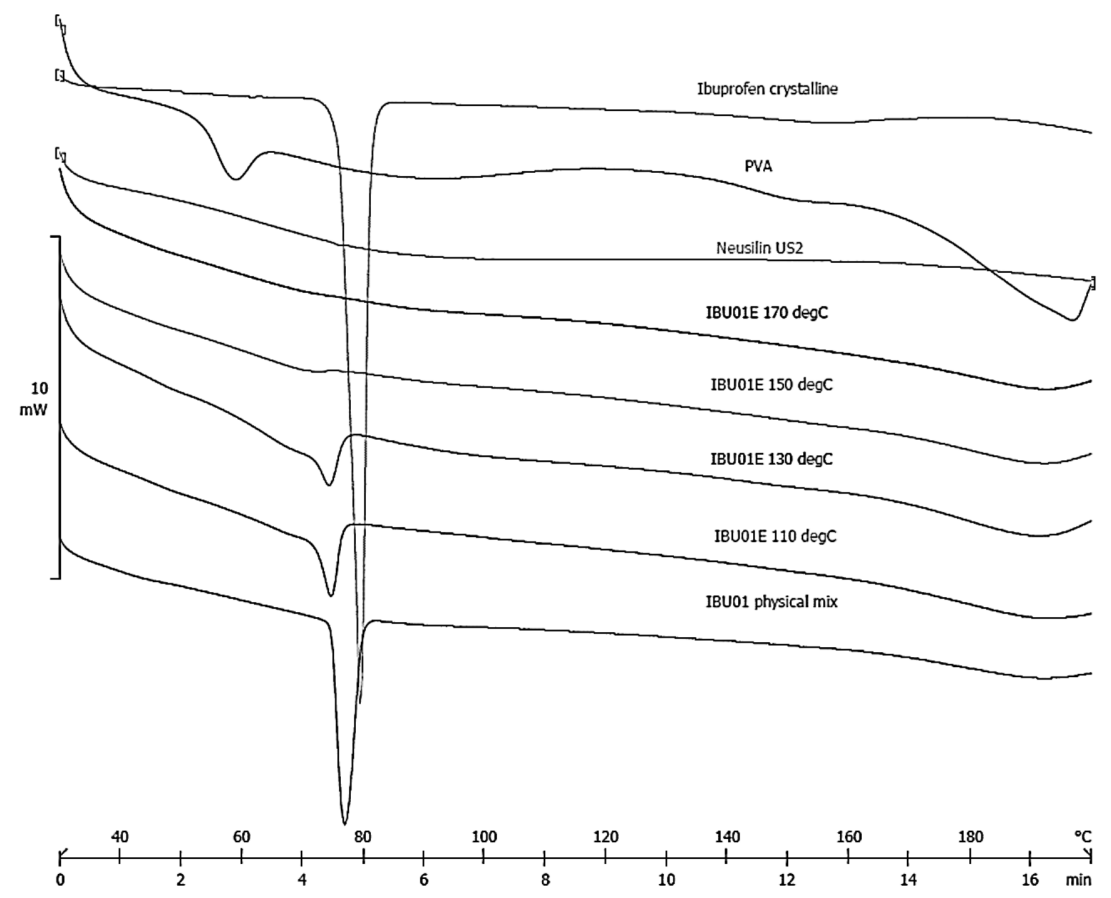

Figure 5. DSC thermograms of IBU01 extrudate obtained at different temperatures (retention time $1.5 \mathrm{~min}$ )

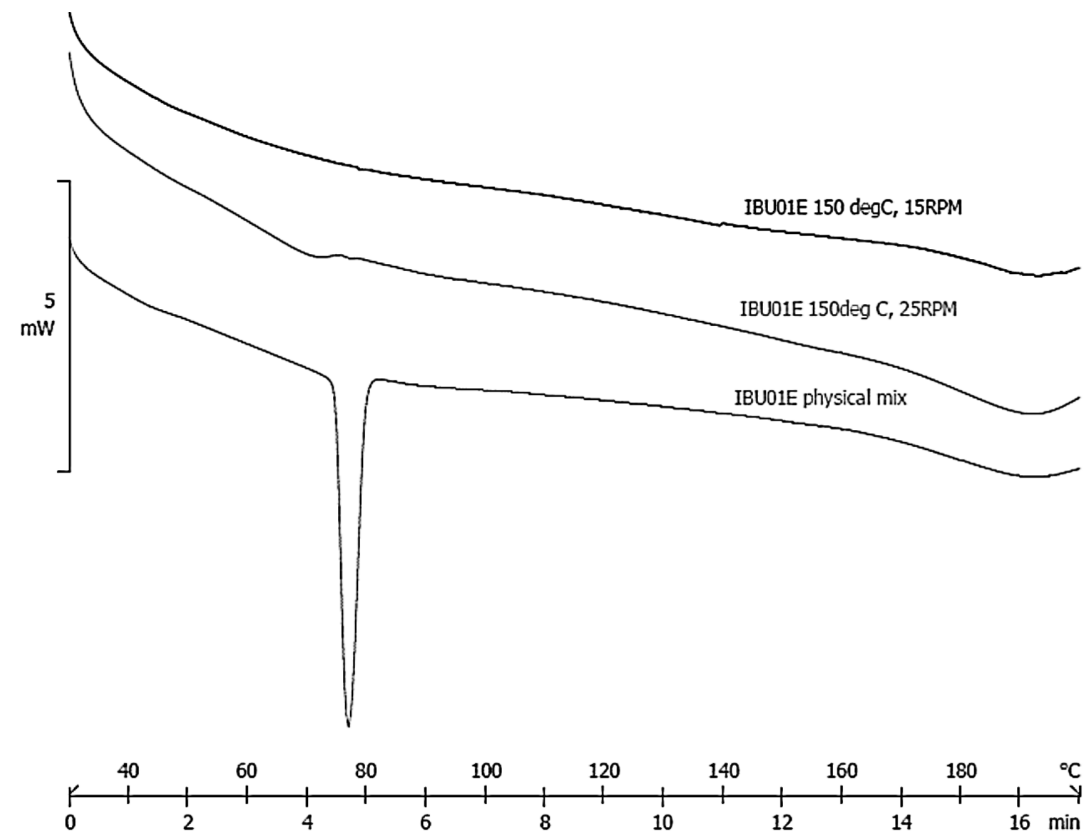

Figure 6. DSC thermograms of IBU01 extrudate obtained at different retention Times (temperature $150^{\circ} \mathrm{C}$ ) 


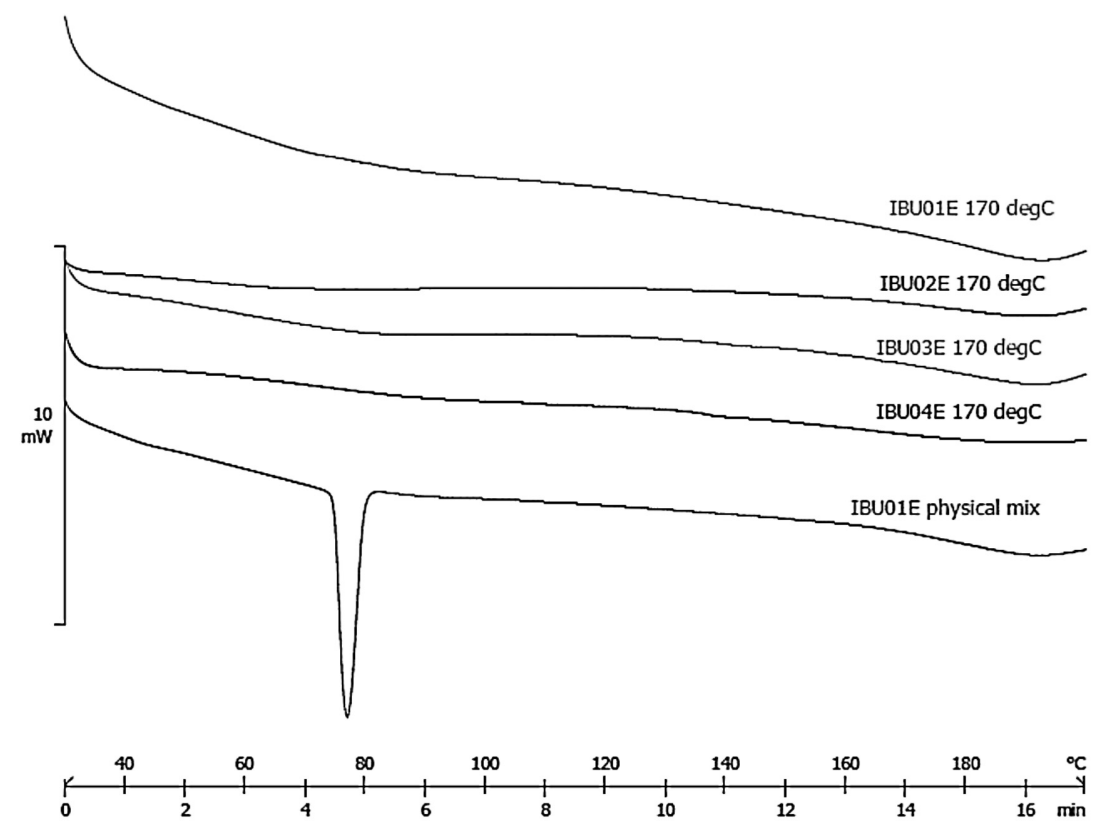

Figure 7. DSC thermograms of IBU01, IBU02, IBU03, IBU04 extrudates and IBU01 physical mix

\section{RESULTS AND DISCUSSION}

\section{Hot plate melting}

Hot plate melting of ibuprofen reveled its physical behavior during melting - solidifying cycle (Fig. 3). Melted down ibuprofen solidifies gradually, creating solid clusters in a still molten mass. DCS thermograms before and after the cycle clearly show the crystalline nature of tested material (Fig. 4). Ibuprofen does not maintain amorphous after melting. Simple vitrification method could not be employed as a technique of amorphization due to spontaneous recrystallization phenomenon.

\section{Hot melt impregnation and thermal analysis}

To overcome recrystallization and maintain ibuprofen in an amorphous form hot melt impregnation process was performed. The effectiveness of this method has been confirmed in the literature (29). Nevertheless there is no data describing hot melt impregnation process with ibuprofen, moreover, there is no information of applying this technique as an amorphous tablets development step.

Temperature profile optimization revealed that only the highest temperature profile $\left(170^{\circ} \mathrm{C}\right.$ in the third heating zone) provided amorphization of tested material. For the lower process temperatures, thermal effects associated with the crystalline ibuprofen presence were visible at the DSC thermograms (Fig. 5).

During the development, it was observed that the temperature is not the only process parameter influencing ibuprofen amorphization. Screws speed (affecting the time of the material passage through the barrel) plays also a crucial role in the process. It was proven that decreasing screws speed form 25 to $15 \mathrm{RPM}$ (1.5 min and $2.5 \mathrm{~min}$ retention time respectively) can compensate for the lower temperature of the extrusion (Fig. 6). As a result of conducted experiments, it was decided to run the rest of the trials on $70 / 110 / 170 / 130^{\circ} \mathrm{C}$ (final temperature profile) and 25RPM of screws speed.

All prepared compositions after extrusion were analyzed using differential scanning calorimetry and compared to the physical mixture containing crystalline ibuprofen (Fig. 7). Endothermic effect visible at around $75^{\circ} \mathrm{C}$ would indicate the presence of crystalline ibuprofen in the extrudate. A Lack of above mentioned thermal effect for all compositions identifies potential amorphous nature of the tested samples. From manufacturing point of view such an analysis also confirms appropriate settings of process parameters.

All prepared extrudates were white to offwhite free-flowing powders, no additional milling/ grinding step was necessary to employ extrudates 
for the tablet compression process. Before the extrudates were reproduced into tablets extensive physical characterization has been conducted.

\section{Scanning electron microscopy}

Scanning electron microscopy has been utilized for visual evaluation of changes, which occurred in the material during the hot melt extrusion process. At first pure raw materials have been micrographed in order to enable visual identification of every single component in the final blends before and after the extrusion process. Ibuprofen is a crystalline needle-like substance, having an elongated shape. Neusilin resembles spheres of a narrow particle size distribution. Polyvinyl alcohol appears as the smallest and the least regular particles having sharp edges.

The scanning electron micrographs of IBU03 and IBU04 compositions before and after extrusion are shown below (Fig. 9 and 10). SEM analysis was used as a tool for examination of the bulk materials surface morphology. IBU03 is a mixture of 3 materials before the extrusion process. After the process results obtained for the extrudate indicate the absence of the crystalline ibuprofen, however particles of agglomerated PVA are clearly noticeable

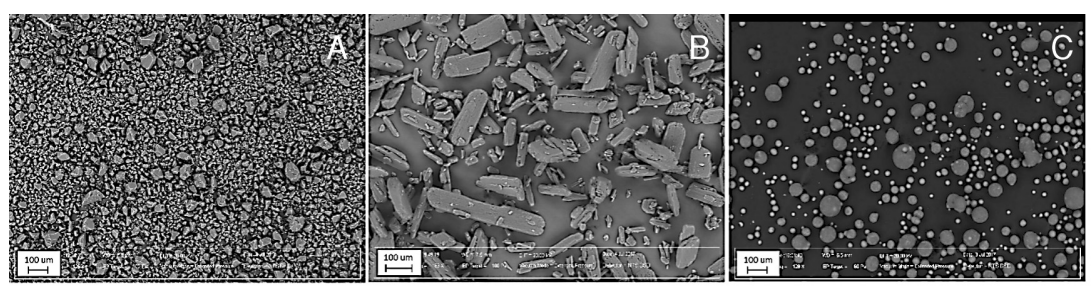

Figure 8. SEM image of A) polyvinyl alcohol (Partec MXP), B) ibuprofen and C) Magnesium aluminometasilicate (Neusilin US2), magnification $\sim 150 \times$

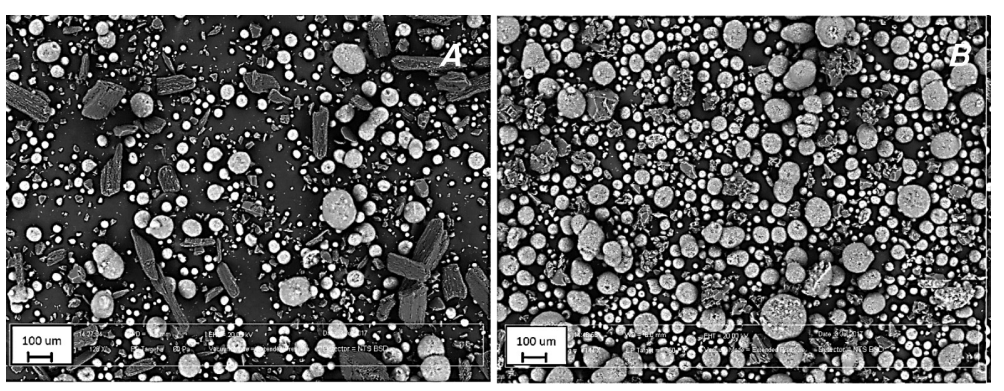

Figure 9. SEM images of A) unprocessed and B) extruded IBU03 composition, magnification $144 \times$

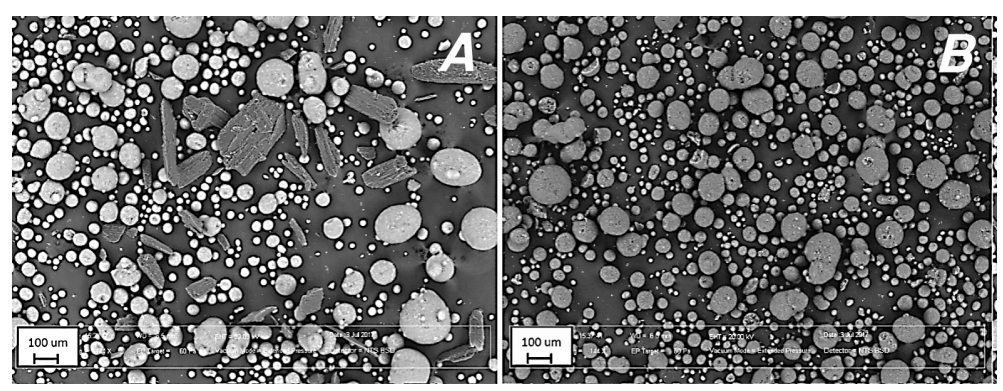

Figure 10. SEM images of A) unprocessed and B) extruded IBU04 composition, magnification $144 \times$ 

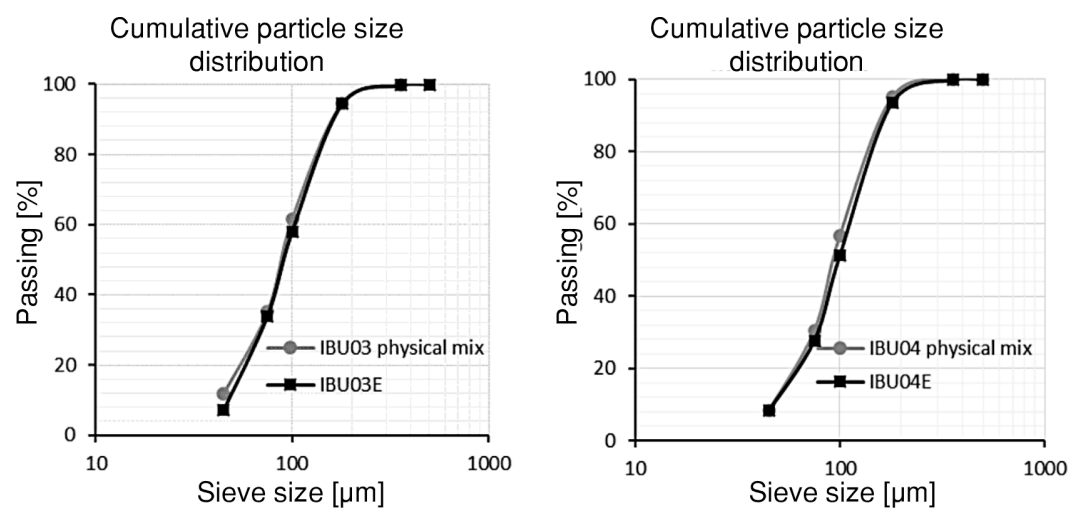

Figure 11. Cumulative particle size distribution comparison for IBU03 and IBU04 materials

Table 2. Specific surface area results.

\begin{tabular}{|l|c|}
\hline \multicolumn{1}{|c|}{ Material } & Average SSA $\left[\mathrm{m}^{2} / \mathrm{g}\right]$ \\
\hline Magnesium aluminometasilicate (Neusilin US2) & $405.7 \pm 4.1$ \\
\hline IBU01 physical mix & $69.9 \pm 1.1$ \\
\hline IBU01E & $27.5 \pm 0.4$ \\
\hline IBU02E & $22.5 \pm 0.1$ \\
\hline
\end{tabular}

next to the spherical Neusilin particles. Presence of the PVA aggregates could be caused by not high enough process temperature and only partial transition of PVA into the liquid state. For IBU04 composition, ibuprofen has been completely incorporated into internal Neusilin pores and therefore after the process, only Neusilin particles were observed. Due to high enough process temperature $\left(170^{\circ} \mathrm{C}\right)$, low melt viscosity and capillary effect forced melted ibuprofen to penetrate Neusilin pores. Similar phenomena were not observed for PVA. Melting point of PVA is at $170^{\circ} \mathrm{C}$ and $\mathrm{Tg}$ is ranging from 40 to $45^{\circ} \mathrm{C}$, therefore complete and efficient PVA penetration of the Neusilin's pores was prevented. Higher temperature profile or longer residence time could help, however, at the same time, it would cause degradation of the active substance.

\section{Particle size analysis}

Particle size analysis has been conducted to visualize differences between materials before and after the impregnation process. Particle size distribution is a very important factor affecting material flowability. In both cases, before and after the extrusion process tested materials showed excellent flowability. PSD measurements were conducted for two batches IBU03 and IBU04, results are shown below (Fig. 11). It can be observed that PSD does not significantly change during the process, despite the observed change on the micrographs. It can be concluded and noticed that all raw materials have similar particle size distribution. The bulk density of the raw Neusilin dominates mixture's volume and determines powder flow properties for the obtained extruded materials.

\section{Specific surface area measurements}

SSA experimental data (Table 2) point to dependence between ibuprofen content, manufacturing step, and SSA measured value. There is a significant difference between the physical component mixture and the same composition procced by the described HME. SSA decreased more than two times for the extruded material. Process temperature forced ibuprofen to melt and occupy available volume of Neusilin pores. The higher ibuprofen content in the extruded material the lower SSA measured value.

\section{X-ray powder diffraction analysis}

$\mathrm{X}$-ray analysis of the prepared extrudates was conducted to examine the crystallinity of the sam- 
ples and confirm their amorphous structure (Fig. 12). Obtained results of IBU01, IBU03 and IBU04 extrudates show a lack of the crystalline phase within analyzed material. Results obtained for IBU02 extrudate show weak signals characteristic for crystalline ibuprofen XRPD pattern. IBU02 composition has the highest ibuprofen to Neusilin ratio. One must mention two probable explanations of this finding. First one is that in this particular case Neusilin pore volume has become overloaded in the course of the process. Due to a lack of internal space remaining Ibuprofen recrystallized on the available

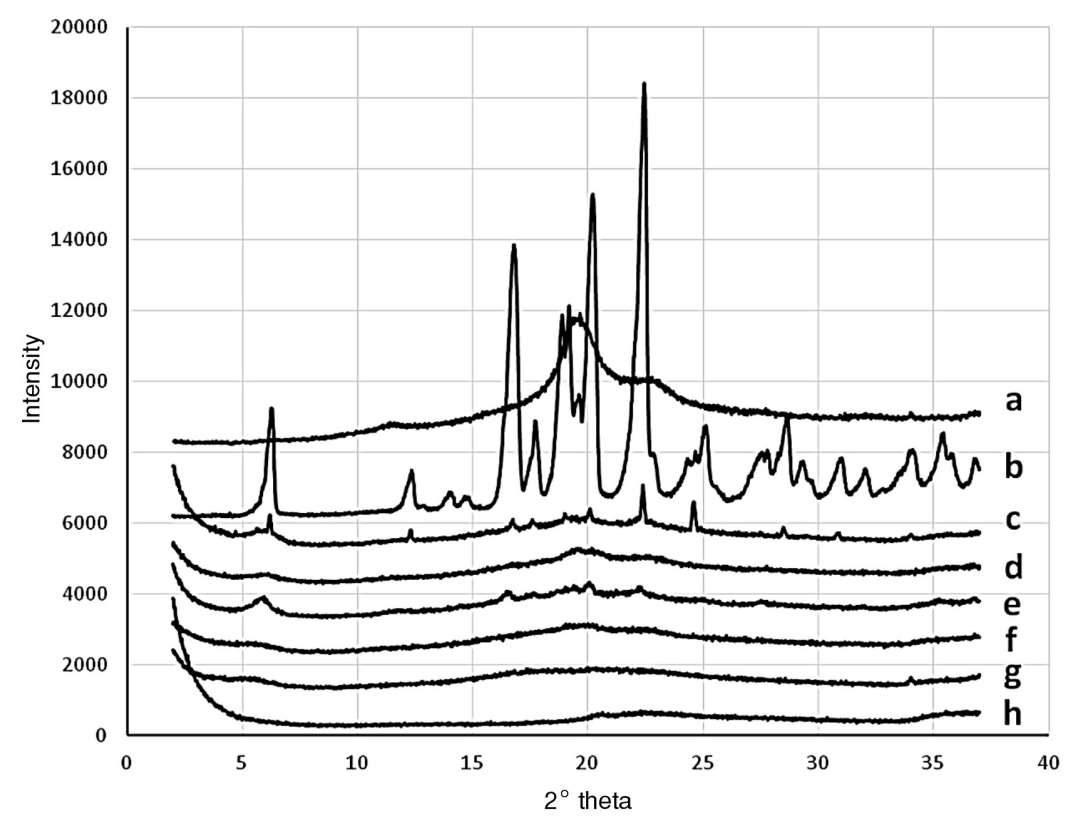

Figure 12. XRPD diffractogram of IBU01, IBU02, IBU03, IBU04 extrudates and crystalline ibuprofen. a) PVA Parteck MXP, b) IBU crystalline, c) physical mix (5\% IBU, 47.5\% Neusilin US2, 47.5\% PVA), d) IBU01E, e) IBU02E, f) IBU03E, g) IBU04E, h) Neusilin US2

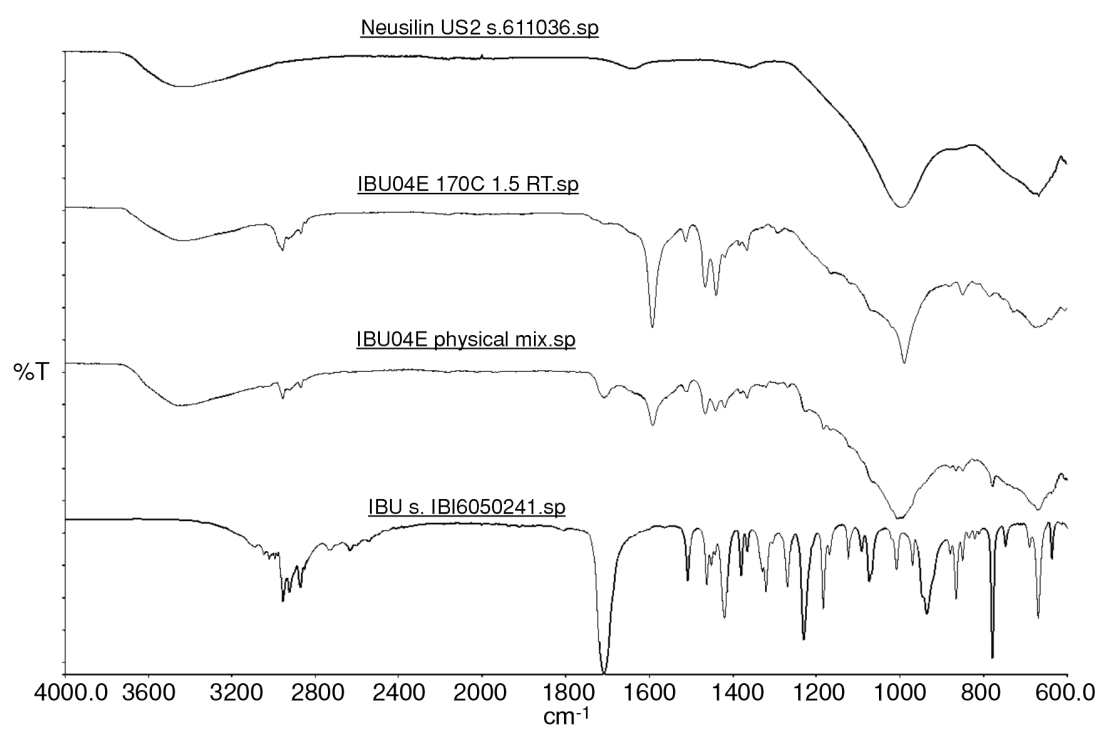

Figure 13. FTIR spectra of pure ibuprofen, pure Neusilin, IBU04 physical mix, and IBU04 extrudate 
Table 3. Physical properties of prepared extrudates with ibuprofen.

\begin{tabular}{|c|c|c|c|c|c|c|}
\hline \multirow{2}{*}{ Batch } & \multicolumn{5}{|c|}{ Type of test } \\
\cline { 2 - 8 } & $\begin{array}{c}\text { Flowability } \\
(\mathrm{s} / 100 \mathrm{~g}) \pm \mathrm{SD} ; \mathrm{n}=3\end{array}$ & $\begin{array}{c}\text { Angle of repose } \\
\left({ }^{\circ}\right) \pm \mathrm{SD} ; \mathrm{n}=3\end{array}$ & $\begin{array}{c}\text { Bulk density } \\
(\mathrm{g} / \mathrm{mL})\end{array}$ & $\begin{array}{c}\text { Tapped density } \\
(\mathrm{g} / \mathrm{mL})\end{array}$ & $\begin{array}{c}\text { Hausner } \\
\text { ratio }\end{array}$ & $\begin{array}{c}\text { Carr's } \\
\text { index }(\%)\end{array}$ \\
\hline IBU01E & $10.6 \pm 0.9$ & $29.8 \pm 1.8$ & $0.34 \pm 0.02$ & $0.40 \pm 0.02$ & 1.18 & 15.0 \\
\hline IBU02E & $11.2 \pm 1.1$ & $30.2 \pm 0.8$ & $0.37 \pm 0.03$ & $0.42 \pm 0.04$ & 1.14 & 11.9 \\
\hline IBU03E & $10.5 \pm 0.6$ & $31.4 \pm 1.1$ & $0.35 \pm 0.03$ & $0.40 \pm 0.03$ & 1.14 & 12.5 \\
\hline IBU04E & $9.8 \pm 0.7$ & $27.9 \pm 1.2$ & $0.38 \pm 0.02$ & $0.41 \pm 0.02$ & 1.08 & 7.3 \\
\hline
\end{tabular}

Table 4. Tablets composition of all prepared batches.

\begin{tabular}{|c|c|c|c|c|c|c|c|c|}
\hline \multirow{2}{*}{ Substance } & \multicolumn{2}{|c|}{ IBU01T-200 } & \multicolumn{2}{c|}{ IBU02T-200 } & \multicolumn{2}{c|}{ IBU03T-200 } & \multicolumn{2}{c|}{ IBU04T-200 } \\
\cline { 2 - 10 } & {$[\%]$} & $\mathrm{mg} / \mathrm{tab}$ & {$[\%]$} & $\mathrm{mg} / \mathrm{tab}$ & {$[\%]$} & $\mathrm{mg} / \mathrm{tab}$ & {$[\%]$} & $\mathrm{mg} / \mathrm{tab}$ \\
\hline Ibuprofen & 32.0 & 200.0 & 43.2 & 200.0 & 38.4 & 200.0 & 48.0 & 200.0 \\
\hline PVA & 32.0 & 200.0 & 19.2 & 88.9 & 19.2 & 100.0 & - & - \\
\hline Neusilin US2 & 32.0 & 200.0 & 33.6 & 155.5 & 38.4 & 200.0 & 48.0 & 200.0 \\
\hline Croscarmellose sodium & 3.0 & 18.8 & 3.0 & 13.9 & 3.0 & 15.6 & 3.0 & 12.5 \\
\hline Magnesium stearate & 1.0 & 6.2 & 1.0 & 4.6 & 1.0 & 5.2 & 1.0 & 4.2 \\
\hline Total & 100.0 & 625.0 & 100.0 & 462.9 & 100.0 & 520.8 & 100.0 & 416.7 \\
\hline
\end{tabular}

Table 5. Physical properties of manufactured ibuprofen tablets.

\begin{tabular}{|c|c|c|c|c|c|c|}
\hline \multirow{2}{*}{ Batch } & \multicolumn{7}{|c|}{ Tablet parameter } \\
\cline { 2 - 8 } & $\begin{array}{c}\text { Mean hardness } \\
\pm \text { SD [N] }\end{array}$ & $\begin{array}{c}\text { Diameter } \\
\pm \text { SD [mm] }\end{array}$ & $\begin{array}{c}\text { Mean thickness } \\
\pm \text { SD [mm] }\end{array}$ & $\begin{array}{c}\text { Mean weigth } \\
\pm \text { SD [mg] }\end{array}$ & $\begin{array}{c}\text { Friability } \\
{[\%]}\end{array}$ & $\begin{array}{c}\text { Average disintegration } \\
\text { time [min:s] }\end{array}$ \\
\hline IBU01T-200 & $118 \pm 5.6$ & $12.11 \pm 0.01$ & $6.39 \pm 0.01$ & $627 \pm 6.7$ & 0.16 & $01: 11$ \\
\hline IBU02T-200 & $122 \pm 5.0$ & $12.05 \pm 0.01$ & $4.72 \pm 0.01$ & $463.0 \pm 3.1$ & 0.17 & $03: 18$ \\
\hline IBU03T-200 & $110 \pm 4.1$ & $12.13 \pm 0.01$ & $5.83 \pm 0.01$ & $522 \pm 2.8$ & 0.15 & $01: 13$ \\
\hline IBU04T-200 & $102 \pm 13.9$ & $12.11 \pm 0.01$ & $4.91 \pm 0.01$ & $420.3 \pm 1.1$ & 0.21 & $00: 42$ \\
\hline
\end{tabular}

external surface. The second one focuses on retention time, a higher amount of ibuprofen in the composition would require a longer processing time for achieving full Neusilin pore penetration. Both concepts require further experiments for obtaining a full understanding of the observed phenomenon.

\section{Fourier transformation infrared spectroscopy}

FTIR IBU04 spectrum was compared to the spectra obtained for pure ibuprofen and Neusilin US2 in order to study the character of the drugexcipient interaction. All spectra are shown below (Fig. 13). In the FT-IR spectrum of ibuprofen, a highintensity band corresponding to the stretching vibration from the carbonyl group can be recognized at around $1700 \mathrm{~cm}^{\circ}(33)$. The intensity of this signal decreases for physical mix and is slightly visible for the extruded material. An interesting signal was observed at around $1600 \mathrm{~cm}^{\circ}$, potentially it is a new band characteristic of the carboxylate ion. It may lead to the conclusion that a molecular interaction between ibuprofen and Neusilin takes place. The band is more intense for the extrudate than for the physical mixture, however, it cannot be determined if a new chemical bond was created during the hot melt extrusion process. There is reported information based on FTIR spectra that ibuprofen salts were formed with other silica materials $(34,35)$.

\section{Tablets compression}

Obtained extrudates were utilized for tablets manufacturing. Proposed formulation contained appropriate extrudate, which constituted the base of the tablet. Besides that each formulation contained 
also $3 \%$ of disintegrating agent (croscarmellose sodium) and $1 \%$ of lubricant (magnesium stearate), no additional diluents were required. All tableting blends were characterized by superior flowability (Table 3), provided by a high percentage of Neusilin based extrudates, tablets composition are shown in the table below (Table 4). Excellent flowability is a great advantage over traditional process involving polymeric extrudates. Moreover, tableting blends were characterized by great compressibility, without sticking tendency, which is often a big obstacle for ibuprofen tablets formulations.

Physical results were very satisfactory. Proper appearance without any defects was the first evaluation. Tableting process parameters were adjusted to obtain tablets of predefined characterization, disin- tegration time shorter than 5 min, hardness in between 100 and $130 \mathrm{~N}$ and friability lower than $1 \%$. Tablet weight was set individually for each batch. Obtained results prove the robustness of the proposed process (Table 5). Different ibuprofen content in the extrudates did not altered physical parameters of the tablets.

\section{Dynamic vapor sorption (DVS) analysis}

IBU03T-200 tablets and raw Neusilin US2 material were subjected to dynamic vapor sorption examination. Both results were compared (Fig. 14). Prepared tablets showed a great improvement expressed in significantly lower water sorption in comparison to the raw Neusilin US2 material, main tablet component, and a highly hygroscopic materi-
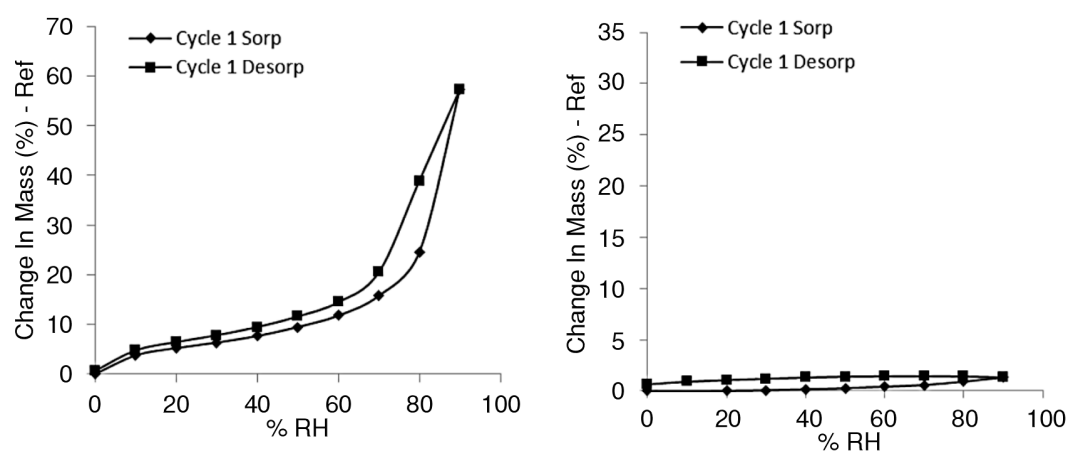

Figure 14. Dynamic vapor sorption isotherm plot at $25^{\circ} \mathrm{C}$ for a) Neusilin US2 material, b) IBU03T-200 tablet

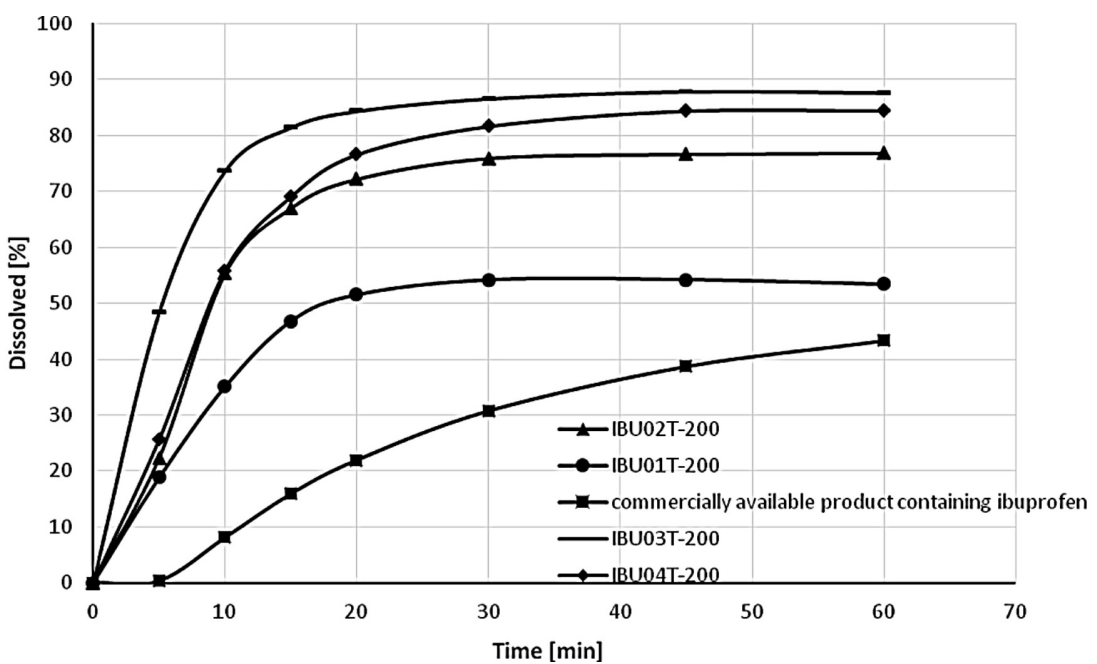

Figure 15. Dissolution profiles for IBU01T-200, IBU02T-200, IBU03T-200, IBU04T-200 and commercially available product containing ibuprofen tablets in $0.1 \mathrm{~N} \mathrm{HCl}, 900 \mathrm{~mL}, 50 \mathrm{RPM}$, paddle apparatus 


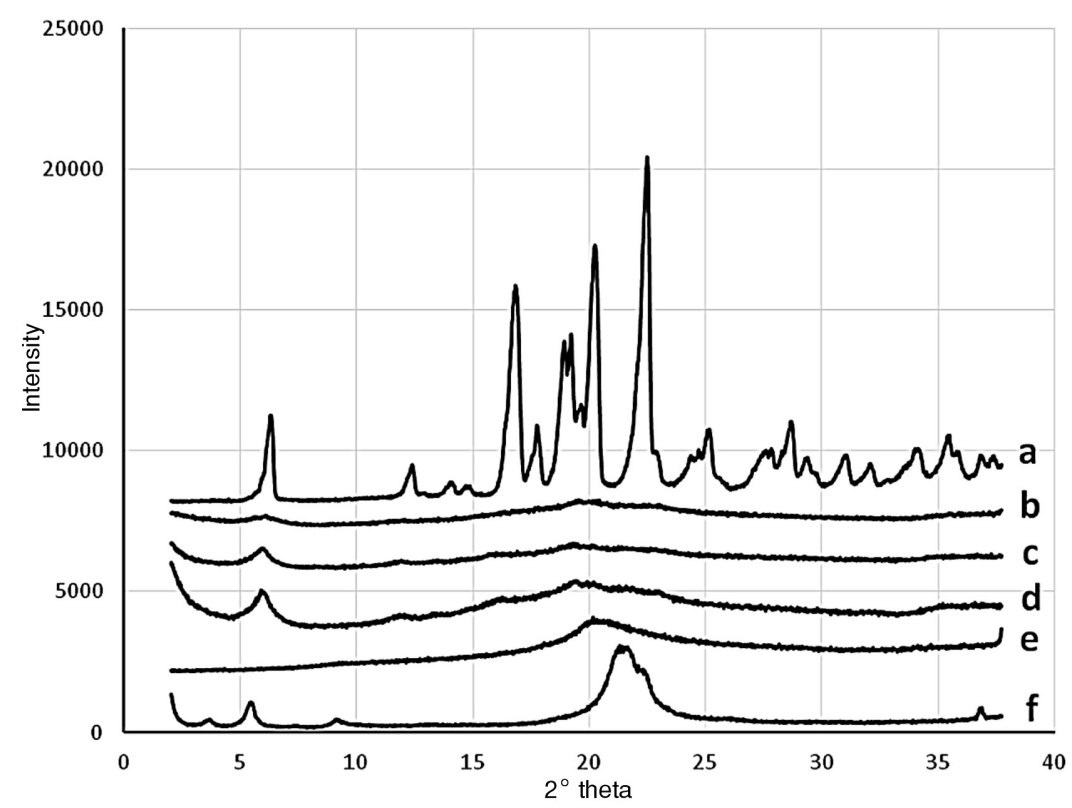

Figure 16. XRPD diffractogram of IBU03T-200 tablets after testing in $40^{\circ} \mathrm{C} 75 \% \mathrm{RH}$ up to 2 months. a) IBU crystalline, b) IBU03T-200 start, c) IBU03T-200 2 months, d) IBU03T-200 1 month, e) croscarmellose sodium, f) magnesium stearate

al. This finding is a result of ibuprofen presence in the Neusilin pores. During the IBU03T-200 DVS experiment water vapor had no internal pore space to condense in and this influenced water mass gain of the analyzed material. A lack of large internal volume is visible in mass change for both materials: less than $2 \%$ mass change for IBU03T-200 and nearly $70 \%$ for Neusilin.

\section{Dissolution test of ibuprofen tablets}

$0.1 \mathrm{~N}$ Hydrochloric acid water solution was chosen as the most discriminative medium for ibuprofen dissolution experiments, the solubility of crystalline ibuprofen at $\mathrm{pH} 1$ is $0.027 \mathrm{mg} / \mathrm{mL}$ (36). Sink conditions were not obtained during the test. Acidic $\mathrm{pH}$ is characteristic to the stomach environment where the tablets have to release Ibuprofen after the administration. In this case faster active substance release means faster therapeutic effect for the patient. The results are shown in Figure 15 . Dissolution results for the tablets containing extrudates are significantly higher in comparison to commercially available product containing ibuprofen tablets. Amorphous form Total release was also much higher due to amorphous or partially amorphous character of the ibuprofen in the tested tablets. Differences between given formulations might be an effect of different ibuprofen to Neusilin ratio combined with PVA. IBU01T-200 tablets were the slo- west among the tested batches, the potential reason is associated with the PVA content. Tablets IBU01T200 contained the highest percentage amount of the polymer, which could create local viscous regions limiting ibuprofen release during dissolution testing.

\section{Stability study}

Tablets IBU03 were packed into PVC blisters and forwarded to stability chambers for thermodynamic stability testing. Blisters have been placed in $40^{\circ} \mathrm{C} 75 \% \mathrm{RH}$ conditions for a period of 2 months. At the beginning and after each month tablets were subjected to an XRPD analysis. Results are shown in Figure 16. It can be concluded that the amorphous ibuprofen slightly crystalizes during the storage in given conditions in the examined tablet. This negative effect can be solved by using high-barrier packaging material (eg. aluminum foil blisters) that will protect produced tablets from the storage conditions.

\section{CONCLUSIONS}

Presented results show an alternative approach to the hot melt extrusion process, which was called hot melt impregnation process. It was possible to produce amorphous high API loaded free-flowing powder. Obtained dissolution results look very promising for prepared ibuprofen tablets in comparison to one of the marketed drug products. It was 
proven that polymer present in the formulation is not necessary for producing a solid dispersion of ibuprofen. However further investigation is necessary for optimization of thermodynamic stability of described systems.

Presented study demonstrates limited solubility enhancing properties of PVA in given application with ibuprofen.

Presented technique could be successfully employed for the development of solid dosage form of different drugs characterized by similar melting point temperature and melt viscosity value.

\section{REFERENCES}

1. Krishnaiah Y.S.R.: J. Bioequiv. Availab. 2, 28 (2010).

2. Kawabata Y., Wada K., Nakatani M., Yamada S., Onoue S.: Int. J. Pharm. 420, 1 (2011).

3. Benet L. Z.: J. Pharm. Sci. 102, 34 (2013).

4. Khadka P., Ro J., Kim H., Kim I., Kim J.T. et al.: Asian J. Pharm. Sci. 9, 304 (2014).

5. Maniruzzaman M., Boateng J.S., Snowden M.J., Douroumis, D.: ISRN Pharm. 436763, 9 pages (2012).

6. Maleki A., Kettiger H., Schoubben A., Rosenholm J.M., Amborgi V., Hamidi M.: J. Control. Release 262, 329 (2017).

7. Jain A., Ran Y., Yalkowsky S.H.: AAPS PharmSciTech. 5, 45 (2004).

8. Zannou E.A., Ji Q., Joshi Y.M., Serajuddin A.T.M.: Int. J. Pharm. 337, 210 (2007).

9. Stella V.J., Nti-Addae K.W.: Adv. Drug Deliv. Rev. 59, 677 (2007).

10. Thakuria R., Delori A., Jones W., Lipert M.P., Roy L., Rodriguez-Hornedo N.: Int. J. Pharm. 453, 101 (2013).

11. Kang B.K., Lee J.S., Chon S.K., Jeong S.Y., Yuk S.H. et al.: Int. J. Pharm. 274, 65 (2004).

12. Pouton C.W.: Eur. J. Pharm. Sci. 11, 93 (2000).

13. Muankaew C., Jansook P., Stefansson E., Loftsson T.: Int. J. Pharm. 474, 80 (2014).

14. Włodarski K., Sawicki W., Kozyra A., Tajber L.: Eur. J. Pharm. Biopharm. 96, 237 (2015).

15. Włodarski K., Tajber L., Sawicki W.: Eur. J. Pharm. Biopharm. 109, 14 (2016).

16. Rawat N., Kumar M.S., Mahadevan N.: Int. J. Recent. Adv. Pharm. Res. 1, 8 (2011).

17. Alam M.A., Ali R., Al-Jenoobi F.I., AlMohizea A.M.: Expert Opin. Drug Deliv. 9, 1419 (2012).
18. Jang D.J., Sim T., Oh E.: Drug Dev. Ind. Pharm. 39, 1133 (2013).

19. Kushida I., Gotoda M.: Drug Dev. Ind. Pharm. 39, 1582 (2013).

20. He X., Pei L., Tong H.H., Zheng Y.: AAPS PharmSciTech 12, 104 (2011).

21. Gong K., Viboonkiat R., Rehman I.U., Buckton G., Darr J.A.: J. Pharm. Sci. 94, 2583 (2005).

22. Lepek P., Sawicki W., Włodarski K., Wojnarowska Z., Paluch M., Guzik L.: Eur. J. Pharm. Biopharm. 83, 114 (2013).

23. Adrjanowicz K., Kaminski K., Grzybowska K., Hawelek L., Paluch M. et al.: Pharm. Res. 28, 3220 (2011).

24. Maniruzzaman M., Rana M.M., Boateng J.S., Mitchell J.C., Douroumis D.: Drug Dev. Ind. Pharm. 39, 218 (2013).

25. Martinez-Marcos L., Lamprou D.A., McBurney R.T., Halbert G.W.: Int. J. Pharm. 499, 175 (2016).

26. Maniruzzaman M., Morgan D.J., Mendham A.P., Pang J., Snowden M.J., Douroumis D.: Int. J. Pharm. 443, 199 (2013).

27. Kellya A.L., Halseyb S.A., Bottomb R.A., Kordea S., Gougha T., Paradkara A.: Int. J. Pharm. 496, 117 (2015).

28. Maclean J., Medina C., Daurio D., AlvarezNunez F., Jona J. et al.: J. Pharm. Sci. 100, 3332 (2011).

29. Maniruzzaman M., Nair A., Scoutaris N., Bradley M., Snowden M., Douroumis D.: Int. J. Pharm. 496, 42 (2015).

30. Neuslin Technical Brochure; Fuji Chemical Industry Co., Ltd., 2015, Japan (www. neusilin.com), ( accessed on 10.03.2018).

31. Panatarani C., Joni I.M., Abdasah M., Rusdiana T., Rachmaniar R.: Marmara Pharm. J. 21, 783 (2017).

32. http://www.merckmillipore.com/PL/pl/product/Parteck-MXP-Polyvinyl-alcohol,MDA_ CHEM-141464\#anchor_COA (accessed on 10.03.2018).

33. Kukulska-Zajac E., Gora-Marek K., Datka J.: Micropor. Mesopor. Mater. 96, 216 (2006).

34. Mallick S., Pattnaik S., Swain K., De P.K., Saha A. et al.: Eur. J. Pharm. Biopharm. 68, 346 (2008).

35. Krupa A., Majda D., Jachowicz R., Mozgawa W.: Thermochimica Acta 509, 12 (2010).

36. Mura P., Bettineti G., Melani F., Manderioli A.: Eur. J. Pharm. Sci. 3, 347 (1995).

Received: 19.09. 2018 